Western University

Scholarship@Western

Department of Economics Research Reports

Economics Working Papers Archive

1995

\title{
Quandaries in the Economics of Dual Technologies and Spillovers from Military to Civilian Research and Development
}

Robin Cowan

Dominique Foray

Follow this and additional works at: https://ir.lib.uwo.ca/economicsresrpt

Part of the Economics Commons

Citation of this paper:

Cowan, Robin, Dominique Foray. "Quandaries in the Economics of Dual Technologies and Spillovers from Military to Civilian Research and Development." Department of Economics Research Reports, 9509. London, ON: Department of Economics, University of Western Ontario (1995). 
RESEARCH REPORT 9509

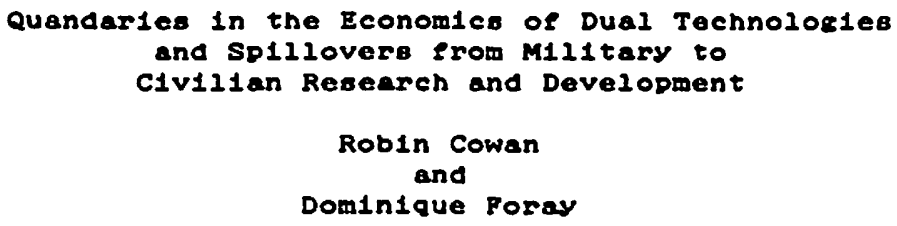




\title{
Quandaries in the Economics of Dual Technologies and Spillovers from Military to Civilian Research and Development
}

\author{
Robin Cowan (University of Western Ontario) \\ Dominique Foray (IRIS; CNRS; Université Dauphine, Paris)
}

\author{
January, 1994. \\ revised June, 1994.
}

\begin{abstract}
In this paper we argue that the "standard" view of the relationship between military and civilian technology is too simple and cannot account for the variety of historical experiences. In order to understand the relationship attention must be paid to two things: that technologies have a life cycle, in different parts of which different types of learning are important; and that the relationship between military and civilian sectors will change depending on the nature of the technology involved, in particular whether it is a process or a product technology. In addition, the standard view does not pay heed to the fact that there are specific organizational requirements to realize these potential crossbenefits. We describe a framework with which to analyse the various features of the relationship taking into account these considerations.
\end{abstract}

\footnotetext{
"We thank Ed Steinmueller for extensive comments on an earlier draft. We also gratefully acknowledge the helpful comments of two anonymous referees. Some of the material in this paper is based on interviews with members of the Direction Générale de l'Armement de France. In particular we thank D. Kechemair for many insightful comments and suggestions. Financial support was provided by the Social Sciences and Humanities Council of Canada.
} 
There is now a sizeable literature whose concern is the relationship between military and civilian technology and R\&D. There have been many studies of the way the two sectors interact, from which a general consensus seems to have emerged. This consensus is that while military research and development may have been of value to the civilian sector in the past, this is no longer the case. Defense $R \& D$ is increasingly specialized and of limited relevance to commercial industry and thus now contributes little to the civilian sector. Our contention is that this view of the contribution of military R\&D to technical changes and economic growth today is too simple. We will suggest that the situation is more complex: there are some technological fields where military $R \& D$ may still generate results useful in the civilian domain, while in others it no longer does.

The phrase "dual technologies" is used here to describe technologies that are developed and used both by the military or space sectors on the one hand and by the civilian sector on the other. The duality of a technology, though, is not typically inherent in the technology itself. "Technologies are not a priori either military or civilian or both. Their character depends on the social network in which they are developed or used" [42].1 It is clear that with this understanding of "dual", a potentially dual technology may never display dual uses. By the same token, the duality can disappear, or it can appear very late in the development and evolution of the social network of the technology. The goal of this paper is to explore various patterns of potential duality and to establish the organizational and informational conditions required to realize this potential. In addition, we describe a framework capable of integrating various patterns of potential duality.

In order to elaborate this framework, it is useful to make distinctions between:

- Potential duality and the realization of this duality.

- Different stages in the technological life cycle: military R\&D has properties which imply that results produced (knowledge, information, competencies) are of general value early in the life cycle of the technology, but the general value of these properties may decrease as a technology matures.

- Different types of R\&D programmes, namely product-oriented, and process-oriented: the potential for duality is de facto limited for the first category (in particular during the later stages of the life cycle), while potential duality may be significant in the case of programmes oriented towards the production of, for example, manufacturing technologies.

One further distinction is worth making. When duality is seen as a relation that sits not in the technology itself, but rather in the networks in which a technology is designed and used,

1 For an extensive exposition of the theoretical principles underlying Smit's argument, see the work of M.Callon and B.Latour. 
one can distinguish between duality and spillovers. "Spillover" refers to a situation in which particular research is done exclusively in one domain and adopted more or less without change in the other. The existence of spillovers, therefore, is not evidence of duality, and might in fact be evidence of its absence. Thus promotion of spillover can be viewed as a policy designed to correct the "duality failure" of a programme of $R \& D$.

It is worth emphasising at the outset that military $R \& D$ and procurement both have opportunity costs. They might displace other military expenditure, other government $R \& D$ or expenditure, or simply private consumption. We will not argue that military $R \& D$ is the best economic use of resources; our argument is simply that to understand the apparent change in the relationship between the two sectors a more sophisticated framework, acknowledging the distinctions made above, is necessary.

\section{I - The Current Debate on the Economic Role of Defense R\&D}

In this section we summarize what we take to be the prevailing view of the relationship between military (and space) and civilian technologies. This is that since the late seventies there has been a radical change. No longer is military $R \& D$ a major engine of technical change; in fact, it may be a serious drag on that engine. There are several arguments underlying this view.

\section{I-1 - Defence R\&D and crowding out}

According to the "crowding out argument", military research seriously weakens the competitive position of countries where military programmes are funded at high levels, by substantially reducing the amount of civilian $\mathrm{R} \& \mathrm{ED}$ investment. ${ }^{2}$ The argument goes as follows: first, military and civilian $\mathrm{R} \& \mathrm{D}$ employ similar resources, such as scientists and engineers; second, the supply of trained scientists to the innovation process is relatively inelastic in the short run; consequently, increases in the military's demand for these resources will result in increases in the wages and prices of R\&D inputs that must be paid by all users of these inputs; ${ }^{3}$ third, the price-elasticity of demand for $R \& D$ inputs is negative, especially in the case of private $R \& D$; as a

${ }^{2}$ The most articulated argument-with a case study and econometric analysis-is provided by F.Lichtenberg [25].

${ }^{3}$ This first set of propositions was articulated by R.Freeman [20] in two econometric studies of the markets for physicists and engineers. Freeman found that federal R\&D spending played a pre-eminent role in determining the starting salaries of both occupations: He estimated that a $10 \%$ increase in real federal R\&D spending would result in an increase in engineers' real salaries of between 2.6 and 4.1\%, and an increase in physicists' real salaries of between 3.3 and $5.6 \%$. 
result, if the price of performing $R \& D$ increases, less $R \& D$ will be sponsored. ${ }^{4}$ Thus, an increase in military $R \& D$ can crowd out civilian $R \& D$.

There are many possible criticisms of this argument: a first addresses the argument based on the hypothesis of the low supply elasticity of scientists in the short run. There are mechanisms for supplementing supply in the short run, including greater use of technicians, immigration of trained personnel and automated design processes such as CAD/CAM. ${ }^{5}$ The degree to which these substitutes mitigate crowding out, though, is a matter of some debate. Another class of criticism concerns the ambiguous nature of the results. This is partly due to the difficulty of distinguishing clearly defence R\&D from other components of military expenditure and, more generally, to substantial weaknesses in the system of definition and collection of data relating to defence $R \& D$; and it is partly due to more general methodological difficulties regarding the underlying economic models. As a result Hartley and Singleton, using Fagerberg's original data set, demonstrate that it is possible to produce contradictory pictures: positive, negative or insignificant effects of defence $R \& D$ on investment $[19,23]$. And in contrast to earlier work, Alic et al. claim that "crowding out of private $R \& D$ by government $R \& D$ has not been demonstrated (at least for recent decades)" [2, p. 130].

Even if we grant some relevance to the crowding out effect-large, rapid increases in the military research, development, test and evaluation budget will drive up the prices of scarce resources needed for civilian $\mathrm{R} \& \mathrm{D}$ and thus reduce the number and the size of civilian projectsit is only the first part of the story. The threat posed by military projects to industrial competitiveness would not be serious if military $R \& D$ were a perfect substitute for civilian $R \& D$. According to the "agnostic" experts, the crowding out effect has no particular economic meaning because the consequences of $\$ 1$ spent in defence $R \& D$ are identical to those of $\$ 1$ spent in civilian $R \& D$ [34]. Thus, in order to assess the implications of the crowding out effect on economic performance, one needs an analysis of the contribution of defence R\&D to global technological development.

\footnotetext{
${ }^{4}$ This second class of arguments is explored by Lichtenberg who assesses the potential impact on US competitiveness of the Strategic Defense Initiative. In fact, there are two contradictory effects from the increase in military R\&D expenditures:

Firstly, the firms tend to increase $R \& D$ outlays in anticipation of the award of competitive contracts, "in order to improve their visibility and their eligibility for government military procurement contracts" [40].

Secondly, firms tend to decrease their R\&D investment by an even greater amount in response to noncompetitive R\&D procurement.

${ }^{5}$ See J.Reppy [36]. She shows, in particular, that with respect to the new "immigration trends from East Europe", there is no evidence that the increases in military spending in the U.S. caused a general shortage of scientists and engineers in the civil sector, although there may have been scarcities in certain specialties.
} 


\section{I-2 - Military R\&D and technological performance}

Econometric analysis of the productivity of military $R \& D$, and qualitative exploration of spillover effects are two kinds of investigations which attempt to demonstrate the negative influence of the crowding out effect on economic performance.

\section{I-2-1 - Military RED and industrial productivity}

Econometric studies appear to show that the economic rate of return to military R\&D investment is very small compared to the return to civilian $R \& D$. In fact, it is claimed, military $R \& D$ has generally had no discernible effect on industrial productivity, whereas civilian $R \& D$ has had a substantial positive impact. Many studies indicate a strong consensus regarding this quasi-absence of effect from military $R \& D$ on industrial productivity [41,26]. According to Schankerman and Pakes, patents from military $R \& D$ are of weak economic value; while estimations by Lichtenberg show that the average returns from private and military $R \& D$ are 33.9 and $0.7 \%$ respectively. In another study, Poole and Bernard present evidence of a negative effect of military innovation on the growth rate of total factor productivity in the aerospace and electronics industries in Canada and the US [35].

\section{I-2-2 - Magnitude and direction of the spillovers}

Analysis of the size, and in fact the direction, of spillovers is pursued in particular by economists who study technical change and industrial policy. ${ }^{6}$ Evaluating the commercial effects of military $R \& D$ poses a certain number of methodological problems though. It is useful to distinguish among direct transfers to commercial applications of specific pieces of hardware [28]; second-order spillover effects (incorporation of results in improved products and processes that have been diffused widely throughout the economy); informational effects of basic research; and last but not least organizational effects, that is the maintenance within contracting firms of a critical mass of scientists and engineers as well as the diffusion of principles of management (such as quality control) from the section assuming military projects to the rest of the firm.

Direct Transfers and Second-order Spillovers: Regarding the estimation of spillovers, some methodological difficulties arise in that the influence of military $1 R \& D$ spending can easily be confounded with that of federal procurement. The benefits that are sometimes perceived to flow from military $R \& D$ are in fact the product of military $R \& D$ and frequently massive military procurement. Nevertheless, many economists argue that the civil importance of military $R \& D$ has declined significantly and that a kind of reversal of the respective roles of civilian and military $R \& D$ has occurred. In the 1950 s, defense research in jet engines and airframes, semiconductors and computers yielded important civilian applications. These were examples of technologies that

${ }^{6}$ See in particular Rosenberg [40], Mowery and Rosenberg [29] and Nelson and Wright [33]. 
could be applied directly to civilian needs, so a direct and almost immediate spillover took place. Another positive factor during this period was a relative similarity in the practices of innovation management (i.e. the cost-performance trade-off). As a result of these similarities, exploitation of economies of scope was possible within firms pursuing both military and civilian R\&D programmes. Because military technology was more advanced than civilian, defence $R \& D$ was highly relevant to commercial industry, and defense $R \& D$ created breakthroughs that advanced U.S. industrial performance.

Over time, however, the size and even the direction of spillovers appear to have changed. The generic similarity of civilian and military technologies has declined, for example in the aircraft area: "As military fighters moved into the world of supersonic speed, they acquired performance and cost characteristics that were increasingly inappropriate for the cost-conscious world of commercial travel" [28]. This divergence applies also to robotics and communication satellites. ${ }^{7}$ It induces a significant diminution of the possibilities of direct and indirect transfer from military to civilian products.

Informational Effects: Informational learning effects have been reduced de facto simply because of the reduced importance of basic research in the total military R\&D budget, which in the U.S. reached a minimum of $3.2 \%$ in 1983 . This contrasts with the $33.7 \%$ of the total federal R\&D budget that is given to basic research. Indeed, between 1965 and 1990, military basic research fell by $1 / 3$ in real terms in the U.S. ${ }^{8}$ This trend in allocation of resources away from basic towards applied research follows the lifecycle of several technologies, in particular aeronautics and microelectronics, both of which have made significant contributions to dual-use over the last decades.

Organizational Effects: Finally, the gap between practices for managing technical change has become more important: the military is willing to spend a lot to achieve marginal improvements, since a "small edge in performance can mean survival" [2, p. 144]. As a result, the U.S. Department of Defense "has been willing to spend a high premium for technological sophistication and performance" [2, p. 141]. This view is supported by data stressing the importance of product innovations and the great inattention to process innovation in defense

\footnotetext{
${ }^{7}$ See for example Hanifin [22], who shows that the robotics applications supported by DOD and NASA (mobility and spatial navigation) are of a little value for civilian use of robotics. Mowery and Rosenberg [28], illustrate generic dissimilarity problems with the example of communications satellites: commercial satellites must have sufficient power to redirect strong signals back to earth, while military communications attach great importance to the covert operation of satellites and therefore have very different requirements.

8It is tempting, but would probably be an error, to ascribe significant parts of this decline to the 1970 Mansfield ammendment, which prohibited military R\&D unless it had a "direct or apparent relationship to a specific military function or operation." In 1970, the Department of Defense judged that only $4 \%$ of its R\&D projects failed to meet this relevance test. (We thank one of the referees for this point.)
} 
R\&D. 9 By contrast, consumers other than the military are often unwilling to pay the high price of slightly pushing back the technological frontier. Many economists argue that this implies a sort of negative spillover, by which scientists and engineers learn bad habits from working on military projects, so the apparent rational response of firms is to keep these two groups separate. ${ }^{10}$ Thus, the differentiation of the learning processes occurring in military and civilian projects seems to imply a decrease in organizational spillovers; since the critical mass of scientists and engineers cannot be reassigned to civilian $\mathrm{R} \& \mathrm{D}$ programs. ${ }^{11}$

It seems then, that the four kinds of spillovers from military R\&D considered above (direct, indirect, informational, and organizational) are rapidly decreasing in magnitude.

In the field of microelectronics, not only the size but also the direction of spillovers appear to have changed as military $\mathrm{R} \& \mathrm{D}$ becomes more and more dependent on technological advances that occur in the civilian sphere. This change may be due to the evolution of the demand structure of microelectronic products. According to Tilton, in $1962100 \%$ of IC demand was military. By 1968, the proportion of military demand for ICs had fallen to $37 \%$ of the total value of production and by 1985 accounted for somewhere between 11 and $14 \%$ of US output. ${ }^{12}$ In this context, the willingness of civilian suppliers to adapt to military needs is noticeably altered. So the principal problem now facing US policy makers is the need to reduce the increasingly long lags in the incorporation of current IC developments in military technology [43].

In conclusion, reductions in generic similarity and the increasing gap between civilian and military management practices appear to have induced the quasi-disappearance of direct, indirect, informational and organisational transfer from military technologies to commercial applications. Furthermore, in certain sectors, the evolution of the structure of demand reinforces this tendency, by changing not only the magnitude but also the direction of spillovers.

9 “In such an environment, suppliers focus on designing new products with new performance, not on improving production efficiencies. Once contracts are awarded, moreover, the conventional commercial pressures to improve efficiency do not prevail. On the contrary, there are significant disincentives for making process improvements; reducing the cost of manufacturing lowers the base on which profits are calculated" [31]. ${ }^{10} \mathrm{See}$, for example Rosenberg and Mowery [28]: "Military R\&D programs may also encourage "learning" of expensive and ultimately inefficients habits, for example, a predisposition to substitute large-scale experimentation and computation for rigourous thought. Such learning spillovers may reduce the effectiveness of R\&D personnel in competitive commercial markets where close attention to cost considerations can be a matter of commercial success or failure."

${ }^{11}$ Data on job mobility argue otherwise, however. In the U.S. the rate at which engineers transfer between military and civilian jobs is 6 percent per year. This compares with a job transfer rate of about 4 percent per year for university graduates who are at least 25 years old. Indeed, $24 \%$ of engineers employed in defense work in 1982 were employed in non-defense work in 1986. (Disaggregated by engineering field, this number ranges from $38 \%$ for non-electrical equipment to $15 \%$ for ordnance.) It is noteworthy that much of this mobility in intra-firm. If there are difficulties of the type claimed, they seem to arise at the managerial level, rather than at the knowledge or experience level. See Lerner [24].

${ }^{12}$ These figures are from Tilton [45, p. 91], quoted in Steinmueller [43]. 


\section{I-2-3 - New developments in technology policy: re-organising the spillovers}

It is now largely accepted among policy makers that civilian technology is more advanced than much defense technology, and that defense $R \& D$ is increasingly specialized and of limited relevance to commercial industry [11, Table 4, p. 20]. This implies a need for new policies, dealing with the organization of military technological dependence rather than with the optimization of the spillovers from military R\&D. Several new initiatives express this major change in US technology policy.

First, there is now a desire to reduce the increasingly long gaps in the incorporation of the civilian "hot product" into military technology. This, for instance, is the goal of the VHSIC program (Very High Speed Integrated Circuits), which focuses on IC technologies that are within the mainstream of IC industry technical development. This focus was deliberate: VHSIC is aimed at returning DOD electronics to that mainstream. Through VHSIC policy makers want to re-shape military demand according to the characteristics of the civilian supply [43].

Second, the changing relationship between military and commercial technologies influenced the decision of the DOD to contribute as much as $\$ 600$ million over six years to the Sematech consortium. Sematech is dedicated to the development of advanced manufacturing processes for commercial memory chips, not military components. Pentagon funding is also prominent in the National Center for Manufacturing Sciences, to which the Defense Advanced Research Projects Agency is contributing $\$ 15$ million over three years. Similar concerns led to the announcement in early 1989 by DARPA that $\$ 30$ million would be allocated to support research in HDTV technologies [29].

Military funding for these programs is based on the assumption that technological advances in process and product technologies and design now flow primarily from commercial to defence applications in these sectors. 13

There is now a strong consensus regarding a radical change in the fundamental nature of the relationship between military and civilian $R \& D$. This has resulted in the existence of a negative effect of defense R\&D on the global development of the technological capabilities of the countries under consideration.

We would like to challenge this view, by developing two kinds of argument:

\footnotetext{
${ }^{13}$ The political context in which this has taken place should be noted. In particular, during the Reagan and Bush administrations, any sort of industrial policy was deemed politically unacceptable, and so any attempts to implement industrial policies had to be disguised as something else, often as military technology policy.
} 
First, potential dual development remains particularly important, i) for emerging technologies; and ii) within the case of emerging technologies, for R\&D programmes which are process-oriented rather than product-oriented.

Second, the realisation of potential duality depends on the configuration and dynamics of the social networks within which the technologies are developed and used.

Thus, the phenomenon of the changing relationship between military and commercial technologies may be wrongly assessed if it is considered as a general breakthrough in the historical evolution of military $R \& D$. The phenomenon under consideration refers to particular technologies at specific stages of evolution, and cannot be extended to the entire population of technologies concerned with dual development and use.

\section{II - Framework}

Our argument has two aspects: first, an analysis of the modes of generation of knowledge, which leads to the representation of a general evolutionary pattern of potential duality, linked with the technology life cycle; and second, an analysis of different types of R\&D programmes, which leads to a distinction between specific patterns of potential duality.

\section{II-1 - Experimentation and rationalization}

The appearance of a new technology is typically followed by a period during which many variants are tried and experimented with. After a period of experimentation, one, or perhaps a small number of variants is selected as standard practice. The selection can be passive, through the market mechanism for example; or active, when a powerful agent decides that a particular variant should be the standard. When a technology fits this pattern two kinds of learning are important. The first is extensive learning, or learning from diversity, which involves experimentation with a wide variety of options and, through the results of which, leads to the elimination of certain avenues of development. The second type of learning can be called intensive learning, or learning from standardization or rationalization, in which attention is concentrated on one technological variant, making it "easier to identify empirical irregularities that point to underlying structural conditions deserving further investigation" [17]. A shift similar to the one described here can be seen in the history of the nuclear reactor technology. In 1955, at the first international conference on nuclear power in Geneva, about 100 types of piles were discussed. Three years later, the number was down to about 12 . When the US Navy decided to produce a nuclear powered submarine, after initial experiments by the AEC with six technical variants, two varieties were considered, and after a single experience with each, only one was used. This variant was intensively explored and developed over the following decades [12]. 
When technological development is viewed in this framework it is clear that the use and development of a technology by the military can have one type of effect in one phase, and a different type in the other. We will argue that in the early phase of a technology, when experimentation is an important part of learning, the military can play a valuable role. Later in the life-cycle of a technology, however, the value of military R\&D is reduced, and the crowdingout argument may have force.

In the early phase of a technology's life, ignorance about it can be extreme, and both military and civilian users, (or potential users), have ignorance about the same things. In order for the technology to be useful to either sector, this ignorance must be reduced, so both sectors have interest in acquiring information about the technology. There are many elements of the technology that are of interest to both sectors, so much of what is learned in either sector is directly applicable in the other. By the same token, generally, the important learning here is about basic principles, or what might be considered generic information about the technology. Thus, many specific things learned by military $R \& D$ are of direct value in the civilian sector, but in addition, this $R \& D$ has value in providing general information about the basic principles of the technology. ${ }^{14}$

As technologies develop, however, military and civilian interests often diverge as the uses of each domain become more and more specialized. As the technological needs of the two sectors become better defined, the degree to which there are elements of the technology common to both will decline, and common features often shift from the system level to the component level. A period of learning through standardization emerges-a user chooses a particular technological trajectory as being most appropriate to a particular need, and this trajectory is explored intensively. Because military and civilian users can standardize on different things, military $R \& D$ is of much less value to the civilian domain during this phase of the life cycle. No longer is $R \& D$ contributing to informational infrastructure. ${ }^{15}$ The information about this technology generic enough to be considered infrastructure has already been generated, as evidenced by the ability of both domains to specialize and pursue their own research agendas.

While military R\&D may have a strongly beneficial effect early in the life cycle of a technology, and a smaller effect later in its life cycle, there is a third type of effect worth mentioning. This is an effect on the timing of the change from one phase of technological evolution to the next. We will argue later that it may be the case that heavy involvement of the

\footnotetext{
${ }^{14}$ Again, military expenditures do have opportunity costs, and there may be no guarantee that military R\&D is the most efficient way of acquiring the learning that we describe here. We argue below that there are reasons to believe that the military is particularly good in this regard. In any case, military R\&D must be justified on the basis that it is good for national defense. The issue at stake in this paper is whether there are benefits beyond those manifest in defense capabilities, to military R\&D.

${ }^{15}$ On the notion of informational infrastructure, see below, Section III.
} 
military in a technology's development speeds up the switch from experimentation to standardization.

With respect to this first feature, a general evolutionary pattern of potential duality can be presented, as in Figure 1: potential duality is evolving along the life cycle, which includes two phases-experimentation and standardization.

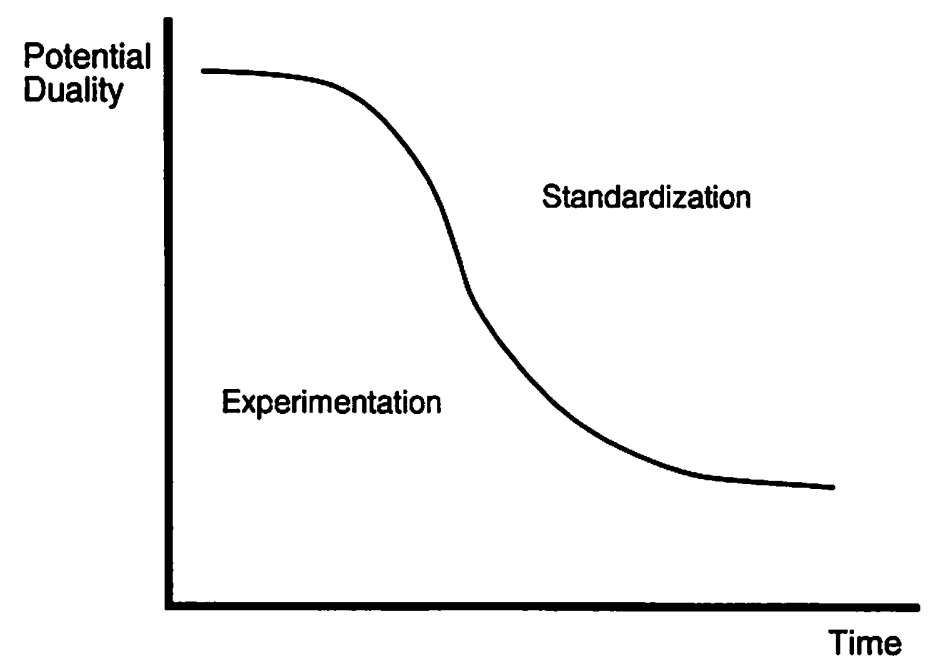

Figure 1: Potential Duality and Stages of the Life Cycle

\section{II-2 - Product versus process-oriented programmes}

Our case studies show, however, the existence of strong differences in the evolution of potential duality, with respect to the nature of the $R \& D$ programme considered.

In the case of a product-oriented programme (for example, $R \& D$ in laser technology can focus on the production of a weapon system; something like the death-ray, or more realistically, target locators for missile guidance systems), potential duality is de facto limited. Though the general pattern is the same as that in Figure 1, in this case potential duality declines rapidly. (See Figure 2a.) The research is immediately focussed on a particular end, and is of a little general value. Then, the divergence in specifications and needs, stemming from the standardization phase, are strong and irreducible.

In the case of process-oriented programmes (for example, $R \& D$ in laser technology can focus on the generation of manufacturing technologies), the duality potential is far more significant. In this case, the latter phase (rationalization) includes two aspects: the standardization aspect (described above) referring to the evolutionary principle of selection and loss of diversity, and the industrial implementation aspect referring to the necessary requirements (reliability, speed and precision) for industrial exploitation of a new technology. In Figure $2 b$, the curve declines less rapidly and to a lesser extent than in the first case. Divergence occurring 
in the standardization phase is less significant, and further, a re-convergence can occur at the end of the cycle, resulting in some recovery of the duality potential during the phase of industrial implementation.
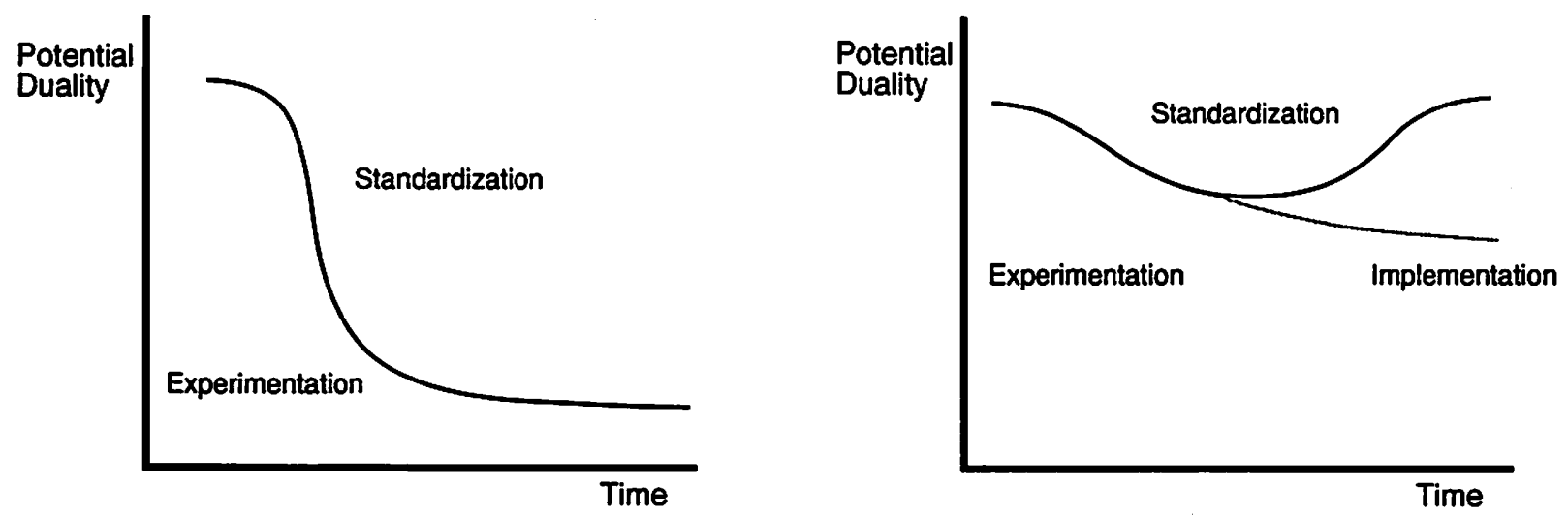

Figure 2: Potential Duality in a) Product Technologies, and b) Process Technologies

This distinction between cases a) and b) in Figure 2 is also of importance when considering policies aimed at increasing the benefits of dual technologies in a national economy.

With regard to the experimentation phase, policy options are similar in the two cases. They deal with the organizational and informational requirements (e.g. mixed laboratories, networks, internal organization of the firm, information disclosure and learning), allowing a system (a firm, a sector, a country) to realize its duality potential.

With regard to the rationalization phase, the duality potential is de facto limited; but the scope of this potential changes considerably, depending upon the type of $R \& D$ programmes considered. A first kind of policy aims at the reduction of the specification gaps between military and civilian domains, so that military standards can meet, for some products, civilian ones. The goal is thus to increase the scope of duality potential during the phase of rationalization. Secondly, policies can deal with organizational conditions facilitating the exploitation of this potential, and with the optimization of spill-overs.

Where the rationalization phase includes a phase of industrial implementation, and thus some opportunity for re-convergence (in the case of process technologies), there is a need for industrial policy to support the supply side in machinery and manufacturing technologies. In the absence of a strong supply side, capable of serving both military and civilian domains, the potential for duality available at this stage will not be exploited.

We will thus investigate, successively, the two phases of the life cycle: experimentation, and rationalization. For each phase, we examine the foundations of the potential for dual use 
and the conditions necessary to realize this potential. We focus finally on the timing effect of dual use.

\section{III - Experimentation}

We argue in this section that military $R \& D$ has the potential to play an important role in encouraging experimentation and diversity in the accumulation of knowledge about emerging technologies. This role gains some of its importance from the nature of the market for technological change and $R \& D$. A market with many firms, each doing its own R\&D, will contain considerable technological diversity, as each firm is likely to have a different approach to the technological problems it meets. A market faces a dilemma, though, when trying to capture the benefits from this diversity. In order that a diversity of approaches in the early stages of a technology be valuable in its future development, the information or knowledge generated by the different experiments must be relatively public. Only when this is the case does the experience of one agent reduce the uncertainties of other agents, and play a part in crossfertilization. But if information is public, there is an incentive to free ride. Future adopters and other experimenters all gain from the publication of experimental results; and in particular, information about the relative merits of this technology can be very valuable in letting future adopters make better-informed decisions. Thus the social value of experimentation is higher than the private value, and the market will under-supply experimentation. ${ }^{16}$

The military, having different incentives, is unlikely to be willing to free ride if it means too little R\&D is performed. In this way, to the extent that information generated by military $R \& D$ is public, the military generates diversity in experiments, and effectively subsidizes $R \& D$. This can happen through several different mechanisms.

\section{III-1 - Similarity of ignorance: building the informational infrastructure}

When new technologies first appear as possible solutions to economic or technical problems, they are typically not well-understood. ${ }^{17}$ The degree to which any particular technology is subject to this uncertainty varies with the extent to which the technology is new and novel, but for some technologies it can be extreme. When this is the case, all users, civilian and military might be said to exhibit a similarity of ignorance, and information generated is of direct use to both.

The research and development that takes place at this stage of a technolog's life can be seen as building the technological-informational infrastructure. In this situation, two types of

${ }^{16}$ See Cowan [13] for a development of this argument.

${ }^{17}$ Many economists have addressed the importance of uncertainty in the process of technical change. See in particular Rosenberg [39] and Cowan [14]. 
information are valuable; defined by Tassey respectively as information about generic technologies, and infratechnologies. ${ }^{18}$ Such information is often provided by the military. This is necessarily the case if the military has an early interest in the technology, since otherwise it cannot use the technology itself.

- First, many examples of generation of generic information by military $R \& D$ can be cited: data about the moderating properties of different materials; the aging of the cans holding fuel rods; properties of metals under long periods of heavy radiation; and waste disposal are of central importance both to military and civilian uses of nuclear power technology, and were generated through R\&D performed by the US military nuclear programme. ${ }^{19}$ A similar situation is thought to exist now with respect to superconductivity. Many of the recent breakthroughs in high temperature superconductivity can trace their antecedents to basic research supported by the military over the past three decades. What made, and continues to make this possible is that the defense program has "technical goals...generic enough to serve commercial as well as military needs" [37, p. 40].

- Second, there are infratechnologies; for example experimental techniques, safety, instrumentation and so on, which are necessary to perform $R \& D$. When technologies are very new and novel, the first stage of their development involves developing research technologies, methods, measurement techniques, and instrumentation, since without them, it is not possible to do further development of the technology, whether military or civilian. Analysts in both sectors use a common set of design and analysis techniques when learning about a technology [1]. Cohendet, Ledoux, and Zuscovitch [8] discuss this activity in the context of research on new materials. They refer specifically to the role of the military in developing control and maintenance processes, and techniques for non-destructive testing, all of which must be mastered before any applied research can be done. Similarly, wind tunnels or computers, both largely developed with government funds, exemplify infratechnologies needed to perform further experimentation and verification of results in other fields. Exploratory military work on nuclear medicine meant that with "a knowledge base, clinical experience and safety standards in place, private firms found the cost of entry into nuclear medicine acceptable" [2, p. 70].

Thus we can see that military R\&D has two sorts of beneficial effects. First, it has value through the knowledge it produces about the characteristics of the technology, which is of direct

\footnotetext{
${ }^{18}$ Following Tassey [44] we will define: i) "generic technologies" as the knowledge which identifies and generally characterizes performance attributes and demonstrates how these attributes will be "bundled" together as an eventual product (in terms of general operating characteristics, product architecture); and ii) "infratechnologies" as the instrumental basis of $R \& D$ including the scientific data necessary for operation of measurement, test, control and trial; methods and research instruments, techniques and knowledge.

${ }^{19}$ See Bupp and Derian [6].
} 
importance to the extent that military and civilian users have common interests. Second, it also has considerable indirect value through its contribution to the information infrastructure.

Early in its life ignorance about how a technology will evolve and interact with the larger technological system is severe for all users, no matter the uses to which they will eventually put the technology. In this case, when so much is unknown, any information about a technology is valuable. This is true even if the information appears to have no direct relevance to the particular use a user is contemplating. (Information about the reaction of one metal to prolonged radiation may be very useful in learning about the reactions of other metals.) Information about any aspect of the technology may be valuable in focussing attention on other useful aspects and possible developments.

\section{III-2 - Technological spectrum}

Technologies can be categorized in two ways-economic and technical, and can fail or succeed in either dimension. One way of characterizing the activity of research and development is as exploring the spectrum or distribution of technological varieties. But since technologies have these two aspects, the distribution that $\mathrm{R} \& \mathrm{D}$ explores is (at least) two-dimensional. When $R \& D$ is performed with a civilian end in mind, exploration is concentrated on varieties most likely to provide large improvements in the profits of potential adopters. The variety that provides the largest expected net benefit to its adopters will be examined first. The same is not true of military R\&D. Here the varieties examined first will be those most likely to turn out to be technically superior to all the rest. We would expect, then, that military and civilian $R \& D$ will explore different parts of the technological distribution. This obviously has a positive effect on the amount of diversity that exists within any technology. ${ }^{20}$ An example of this effect exists in the development of new composite materials. The space program was concerned with weight and heat-resistance in composites, and was determined to have the most effective material available. The production costs of the products of this research were very high, though, so it had few commercial applications. Thus this part of the technological spectrum was not much explored by the civilian sector. As it turned out, as the level of production increased, the costs of production fell, through learning by doing and learning by using, and civilian uses for the (now less expensive) materials emerged [8, pp. 60ff.]. In transistor technology, the main supporter of the gallium arsenide technology has been the military [8, pp. 251ff.]. This is due to the fact that gallium arsenide, while more expensive than doped silicon, gives better performance in several important ways: it is faster and resistant to electro-magnetic pulse. Whether knowledge generated by this $R \& D$ is transferred to the civilian sector remains to be seen, but it provides

${ }^{20}$ This effect relies on the relative cost-insensitivity of the military. To the extent that costs become important in decisions about military technology, and they seem to be becoming so, this effect will be mitigated. 
another example of the way in which the military, for various reasons, often looks at different parts of the distribution of possible technical trajectories.

The diversity produced in this way, though, by definition, is unlikely to have an immediate direct impact on the efficiency of civilian technology (if it were likely to be economically valuable, then some firm would do the experimentation that leads to it). As Cohendet, Llerena and Sorge have argued, diversity is valuable for more than simply direct application to new technologies. It is valuable also for the cross-fertilization of ideas and the generation of information of a type that otherwise would not exist. The information, rather than the technological variants that lead to its generation, is what is valuable, and military $R \& D$ can generate different sorts of information than does civilian $R \& D$ [7].

\section{III-3 - Effects on the research community}

One of the important aspects of early military $R \& D$ stems from the way in which it affects the general research environment. Utterback and Murray argue that by its strong interest in integrated circuits, the military effectively created the early US research capacity. By subcontracting research to private firms and to universities, the military is doing two things. First, it is creating a positive environment for research and innovation in the area. This is so for both intellectual reasons - a new field of research, in which little is known and the possibilities are large and exciting, is publicized; and mundane reasons-there is a large amount of research money with which a scientist can equip a lab and so on. The second effect is that of training a core of researchers and generating a critical mass of the skills needed to pursue the development of the technology. Funds are available to perform the research and support graduate and postdoctoral students, which has the effect of creating a large stock of human capital specialized in the technology. ${ }^{21}$ This human capital, of course, is of tremendous value to any firm wanting to introduce a product using this technology into the civilian market. It makes it possible in the first place, and it decreases the costs of future innovations in that technology. 22

In the system of science, characterized by strong positive feedbacks (like the "Matthew Effect" and cumulative advantage), any support from the military may generate significant dynamic effects on the evolution of those research institutes which have benefited from the allocation of military resources. ${ }^{23}$

${ }^{21}$ For a discussion of these effects see Bach et.al. [3]; Utterback and Murray [46]; and Mowery and Rosenberg [28].

${ }^{2}$ There is also a directional effect of of early military R\&D. Scientists and engineers recruited to do research early in the life of a technology quite naturally introduce that research into the courses they teach. It can soon find its way into curricula of science and engineering education, thereby pushing the training of the next generation of scientists and engineers in a particular direction. See Barus [4, pp. 3-9].

${ }^{2}$ See David [16]. 


\section{III-4 - Organizational requirements and policy issues in realizing the dual potential}

Military $R \& D$ provides experimentation which produces valuable information, allowing civilian R\&D to learn more effectively from diversity. The potential benefits described here, however, can only be realized if certain organizational and informational requirements are fulfilled; that is, if the social networks have such a configuration that they link the R\&D programmes undertaken in the civilian and in the military domains. These conditions deal with: The organization of research. There is a need for i) government funded mixed laboratories, ii) networks of scientists and engineers increasing the frequency of the interactions among them, iii) internal organizations of firms facilitating joint-development and economies of scope, as well as iv) the development of improved systems of information retrieval and promulgation in order to promote a more effective use of the new knowledge created in one of the two domains. In the absence of those organizational forms, potential benefits from dual development are very difficult to realize.

The information disclosure problem. Classification and secrecy practices generate particular difficulties in transferring knowledge from military to civilian R\&D. Optronics is a case in point. It is an area of basic research with a strong potential for dual development, in subfields such as adaptive optics, optics for computers, inter-satellite communications, very large telescopes, isotopic separation and laser applications for manufacturing technologies. In France, civilian and military programs were launched early in the seventies and the research was carried out independently by the CNET (Telecommunication) in the civilian area and by a partnership between the DGA (Direction Générale de l'Armement) and the CEA (Energie Atomique) in the military area. Clearly the effective realization of duality was dependent upon the construction of networks among the military and civilian institutions and the declassification and disclosure of a number of fundamental results of the military research. However, these conditions were not fullfilled and as a consequence today there is a lack of a common knowledge base and infratechnologies. ${ }^{24}$ In contrast, in the U.S., DARPA (now ARPA) was established precisely to explore the early-stage development of new technologies. DARPA is separate from the military services and its research is carried out by universities and the private sector. It was thus organized in a way that "minimized bureaucratic obstacles to program success." [30, p. 62] Historically, DARPA has performed basic research on many dual-use technologies and its research has been of benefit both to military technology and the civilian sector. This role was changing in the late 1980s, though, as the U.S. administration began to express doubts about DARPA's value as an agency concerned with dual technologies. The current Clinton

${ }^{24}$ Gaillard [21]; on the U.S. policy in this field see [32]. 
administration seems to view ARPA more favourably, so its role as explorer of young technologies may be revived.

\section{IV - Rationalization}

What is the potential for duality at the next stage of the technological cycle, including standardization and (for process technologies) industrial implementation phases? By definition, opportunities for dual development exist: when there are increasing returns to adoption, typically, the more users who adopt one technology or standard, the greater the benefit to each of those users. Thus it might be that dual technologies have scope for greater benefits from standardization since there are more users adopting the technology than is the case for non-dual technologies. Capturing more benefits from standardization than a non-dual technology, though, requires the adoption of the same standard for military and civilian uses of the dual technology.

As suggested above, however, the likelihood of this requirement being met depends significantly on the orientation of the $R \& D$ programme (product or process). Thus, the existence of various patterns of potential duality may be associated with the distinction between the product-oriented and the process-oriented programmes. Consequently, we will treat separately these two patterns of potential duality.

\section{IV-1 - Product-oriented programs of R\&D: the evidence of technological divergence}

In product-oriented $\mathrm{R} \& \mathrm{D}$ programs, almost by definition, potential duality is low: divergence frequently occurs at the rationalization stage. Discussion of communication satellites, robotics, or infra-red technologies show that weapons systems typically have different functional requirements from civil technologies: the generic similarity of specifications and uses is progressively reduced as the technology approaches standardization. ${ }^{25}$ Even when military and civilian technologies have common functional requirements (e.g. transport technologies such as trucks, planes and ships), the military has (or thinks it has) different auxiliary requirements stemming from conditions of combat (extremes of weather, portability and transportability under adverse conditions). There is thus a little scope for potential duality: the process of learning from standardization cannot be based on the entire population of technological units for a given dual technology. Two subsets (a civilian one and a military one) emerge and the magnitude of the learning process becomes limited to the boundaries of these subsets, respectively.

${ }^{25}$ Mowery and Rosenberg [28, pp. 148-149], show that in communications satellites, military priorities now differ considerably from civilian needs. 
One could argue that any potential for duality is likely to be found at the level of components. In the case of large technical systems, some generic parts of the dual technology may be designed under a common (military and civilian) standard, even if many of its uses and specifications are different. Thus, the properties of (non-)duality are strongly affected by the level of aggregation. In the case where some components are generic, the benefits from learning by standardization may be higher if the technology is dual than if not.

\section{IV-2 - Process-oriented R\&D: potential duality in industrial implementation}

As suggested above, the scope for duality is much greater in process-oriented programs: product characteristics may diverge, but one can often make different products with the same or similar technologies. Here, the potential for duality is particularly important at the stage of the industrial implementation of the new technology. The scope of duality includes generic issues dealing with new process capability, improved quality, reliability and durability, reduced lead times, reduced procurement costs, enhanced manufacturing flexibility, avoidance of adverse side effects, improved management systems [10]. Several Air Force programs offer examples of welldirected dual technological development that yielded new products and product features, while reducing manufacturing cost and increasing quality: new processes for unusual materials; flexible machining of parts in short runs; noncontact gauging and testing technologies to improve inprocess quality control; and production of composite structures. Laser based manufacturing technologies provide other good examples of a duality potential. Similar problems-metallurgical feasibility, process implementation, techno-economic evaluation-generate a technological convergence among military and civilian domains. ${ }^{26}$ Similarly, "most of the essential elements of flexible manufacturing derive from technologies first pursued and paid for out of the American military budget" as the Air Force attempted to reduce to cost of airfoil manufacture [27]. Part of this technology underlies the current numerically-controlled machine tool industry [2, pp. 4142; also Ch. 10].

Potential duality takes the form here of economies of scope in development and industrial implementation of the technology under consideration.

\section{IV-3 - Organizational requirements and policy issues to realize the dual potential}

In product oriented $R \& D$ programs there are actions on technological standards that may be of value in realizing the potential for duality. The goal should be to "force" convergence among the standards from civilian and military domains, through two possible routes. Military specifications can be relaxed, which in turn involves altering military aspirations to

${ }^{26}$ The process of technological convergence, based on the existence of similar technical problems among different industries, was studied by Rosenberg [38]. 
invulnerability. This may be possible for common devices and mechanisms (such as cars, trucks, etc). Convergence can also be achieved by "hardening" civilian standards, as in microelectronics and automation [9].

With regard to the industrial implementation phase for process-oriented $R \& D$ programs, there is also a window for industrial policy. The question is to support the supply side in machinery and manufacturing technologies. In absence of a strong supply side, capable of serving both military and civilian domains, the potential for duality at this stage cannot be exploited. Within the DOD in the U.S., the Manufacturing Technology Program (MANTECH) has been the primary program for upgrading the long-term manufacturing technology available to the U.S. industrial base [10].

\section{V-Dual development and timing}

It was mentioned above that military $R \& D$ can have an effect on the timing of the switch from the experimentation stage to the standardization stage of a technology. It is important to distinguish between "event time" and "calendar time" when discussing this effect. The point here is that the optimal time to change regimes depends on the amount of experimentation that has been done with different variants of the technology. Thus the significant events are experiments. Since many experiments can be done simultaneously, calendar time and event time can diverge. It is by now well-known that when users are forced to choose between technologies in an atmosphere of uncertainty regarding their relative payoffs, the market will under-supply experimentation. ${ }^{27}$ It has been suggested that when important technology competitions are taking place an appropriate policy for governments to follow is to delay standardization, and prevent the market from locking in to one technology too early [5]. Military programmes can be instrumental for this kind of policy. In particular, the military can mitigate the effect of premature lock-in in two ways. First, by performing many experiments at the same time the military may cause standardization earlier in terms of calendar time, but later in terms of event time. Second, by continuing to experiment after market standardization, it can provide a potential exit from lock-in. In this case, military R\&D can be considered as a tool to maintain technological variety.

\section{V-1 - Effects of military experimentation in delaying the switch}

Because the military is large, it has resources to support several technologies in the early stages of their development and can thereby promote later lock-in in event time. ${ }^{28}$ This can be a very effective subsidy to the civilian users of the technology. Military development and use

${ }^{27}$ See above, or Cowan [13].

${ }^{28}$ See Cowan [12] for a discussion of nuclear reactors for example. 
pushes technologies quickly along their learning curves, lowering the costs for the later, civilian adopters. When the military supports more than one technology in the development phase, it increases the choice of civilian users, especially in the case of new, complex and expensive technologies. From the point of view of market participants, the military can be described as having an unusual criterion by which it judges technologies. As suggested above ("technological spectrum"), in many cases, cost is not really an object, rather, the search is for the technology that performs best from some technical point of view. Thus the military is less prone to be locked in to one technology by financial concerns. By developing several technologies simultaneously, the moment of decision for the market is effectively put off, as technologies are allowed to enter the market developed to the point that the adoption decision is based on how well technologies fit the needs of the market, rather than how quickly the R\&D for that technology can be (or has been) performed.

\section{V-2 - Potential exit from lock-in}

The military is extremely risk-averse, in the sense that the 'costs' of failing to find the best technology (in the technical sense) can be very high. It is therefore willing to continue experimenting long after a market would have standardized on one technology. By continued experimentation, the military can allow laggard technologies to leapfrog leading technologies. To the extent that experimentation performed by the military generates results and knowledge transferable to the civilian sector, the activities of the military in this sphere can provide an avenue of exit from technological lock-in. The military, then, can provide what the market fails to provide, and in effect, can intervene in the market to do the job that the policy maker would do in order to correct the market failure, and delay standardization.

Similarly, the military may pick up a technical variant that is discarded in the civil domain. If we look at many modern technologies that have reached the standardization phase of their life-cycles, military technologies are often one or two life cycle stages behind commercial technologies. ${ }^{29}$ This may be considered as an effective tool allowing the maintenance of some diversity, including technologies that have been locked out of the commercial market. In some cases, this diversity may be very useful in the future if new advances require knowledge stemming from the use of the locked-out technology. This is exactly the case of the new hypersonic aircraft project based on anaerobic technology (the statoreactor). This technology was excluded in the sixties when the aerobic technology (the rocket engine) was thought to have the best potential for hypersonic flight. Development of the statoreactor continued, however, through

${ }^{29}$ See for example the case of integrated circuits: the 256K DRAM is in saturation stage of the product life cycle for civilian use, while it is yet in the maturity stage for military use. 
the military use of missiles. This has preserved and generated knowledge about this technology, which is today critical in order to move quickly along the learning curve.

\section{V-3 - Fewer orphans and earlier lock-in: other effects of dual use on timing}

In order to prevent premature lock-in on a wrong technology, the policy maker would want to experiment with a number of systems. This leads to a problem. The policy maker will eventually decide in favour of one system over all others after a number of experiments have accumulated, but this will anger those producers or users who have suffered losses as the result of investing in a technology that was discontinued. 30 Clearly, the number of these potential orphans will decrease to the extent that experimentation is performed in the military rather than the civilian domain.

In calendar time, the military can promote early standardization. In cases in which the military considers the technology important, and immediately valuable, it will conduct many experiments simultaneously. Because the optimal lock-in time is determined by the amount of experimentation that is performed, simultaneous experimentation implies that in calendar time, the optimal lock-in date is earlier than it otherwise would have been. Sufficient knowledge has been generated by military experiments to allow civilian adopters to make rapid decisions about which technological variant should be adopted. In this way, the benefits from standardization arrive earlier, which, due to discounting by civilian agents, raises the value of the technology to them.

Early adoption, though suboptimal from an ex ante point of view, may not be bad from an ex post point of view, if the technology chosen is a good one. In general, though, due to the fact that military uses of technology tend to be different in nature, and have different constraints placed on them than do civilian, we should not expect that early adoption decisions by the military will lead to 'good' civilian technologies. For example, in military use of nuclear power, reactors must be compact and light, in order to be used as on-board motive power. Neither of these constraints bind civilian users of nuclear power though, so in making its adoption decisions, criteria which are important for the military have no economic value. As it turned out, these considerations (along with several others) have locked the civilian nuclear power market into a technology that many claim is inferior to other technologies that could have been developed. 31 If the particular needs of military use feature strongly in an early adoption decision, the learning that follows extensive use will give the chosen technology an advantage in competitions with other technologies. The fact that civilian adopters discount the future may be sufficient to force them to see the development costs of the other technologies as too great to

30 See David [15] for a general discussion of angry technological orphans.

${ }^{31}$ See Cowan [12] for the details of this history. 
bear, even though, from the civilian point of view, the characteristics of the leading technology are thought to be less than perfect.

\section{VI - Conclusions}

The commonly held view that military and space R\&D now provide few benefits to the civilian sector, and indeed if benefits flow they do so in the other direction, suffers from overgeneralization. It fails to account for the general diversity of dual relationships: potential dual benefits occur in different ways at different points in the life cycle of a technology; and potential dual benefits differ depending on the very nature of the technology, whether it be product or process oriented. In addition, the standard view does not pay heed to the fact that there are specific organizational requirements that must be met to realize this potential at the different stages of the trajectory. In this paper, we have attempted to provide a framework with which to analyse the various patterns of potential duality .

We have argued that the dual relationship is important in at least two different cases. Early in the life of a technology there are large gains to be had from the extent and diversity of different approaches to learning about that technology. Here duality can be beneficial. Further, when the technology is a process technology, benefits can occur later in the life cycle, when learning about it takes the form of rationalization of approaches, provided military and civilian standards or needs are sufficiently similar. 


\section{REFERENCES}

[1] J. Alic, The Federal Role in Commercial Technology Development, Technovation 4 (1986), 253-267.

[2] J. A. Alic, L. Branscomb, H. Brooks, A. B. Carter and G. L. Epstein, Beyond Spinoff: Military and Commerical Technologies in a Changing World (Harvard Business School, Boston, 1992).

[3] L. Bach et al., Problematique d'Evaluation des Effets Iduits d'Un Grand Programme de R\&D: Une Application au Programme Spatial Europeen in: J. De Bandt and D. Foray (Editors), L'Evaluation Economique de la Recherche et du Changement Technique, Editions du CNRS, 1991.

[4] C. Barus, Military Influence on the Electrical Enginnering Curriculum Since World War II, IEEE Technology and Science Magazine (June 1987).

[5] S. Besen, R. Cowan, G. Ferné and D. Foray, Information Technology Standards: The Economic Dimension (OECD, 1991).

[6] I. Bupp and J. C. Derian, Light Water: How the Nuclear Dream Dissolved (Basic Books, 1968).

[7] P. Cohendet, P. Llerena and A. Sorge, Technological Diversity and Coherence in Europe: An Analytical Overview, Revue d'Economie Industrielle 59 (1992).

[8] P. Cohendet, J. Ledoux and E. Zuscovitch, New Advanced Materials: European Dynamics and European Strategy (Springer-Verlag, London, 1988).

[9] M. Collombet, L'adéquation de l'offre des produits standards à la demande militaire: la politique d'un industriel, L'Armement, Special Issue: Les Technologies Duales 29 (1991).

[10] Commission on Engineering and Technical Systems, Manufacturing Technology: Cornerstone of a Renewed Defense Industrial Base (National Academy Press, 1987).

[11] Council on Competitiveness, Gaining New Ground: Technology Priorities for America's Future (1991).

[12] R. Cowan, Nuclear Power Reactors: A Study in Technological Lock-In, Journal of Economic History 50 (1990).

[13] R. Cowan, Tortoises and Hares: Choice Among Technologies of Unknown Merit, Economic Journal 101 (1991).

[14] R. Cowan, Technological Variety and Competition: Issues of Diffusion and Intervention, in: OECD, Technology and Productivity (Paris, 1991).

[15] P. David, Some New Standards for the Economics of Standardization in the Information Age, in: P.Dasgupta and P. SAtneman (Editors), Economic Policy and Technological Performanc (Cambridge, Cambridge University Press, 1987).

[16] P. David, Positive Feedbacks and Research Productivity in Science: Reopening Another Black Box, CEPR Discussion Paper, Stanford University (1993).

[17] P. David and G. Rothwell, Performance-Based Measures of Nuclear Power Reactor Standardization, CEPR Publication No. 247, Stanford University (1991).

[18] P. David, D. Mowery and E. Steinmueller, Analysing the Economic Payoffs from Basic Research, Economics of Innovation and New Technology 2(1) (1992).

[19] J. Fagerberg, International Competitiveness, Economic Journal 98 (1991). 
[20] R. Freeman, Supply and Salary Adjustments to the Changing Science Manpower Market: Physics, 1948-1973, American Economic Review 65 (1975).

[21] M. L. Gaillard, Stratégies technologiques et recherche française en optronique, DGA-DRET, (Mars 1992).

[22] L. Hanifin, The Paradox of American Manufacturing, The Challenge to Manufacturing (National Academy of Engineering, 1988).

[23] K. Hartley and J. Singleton, Defence R\&D and Crowding-Out, Science and Public Policy 17(3), (1990).

[24] J. Lerner, The Mobility of Corporate Scientists and Engineers Between Civil and Defense Activities: Evidence from the SSE Database; Science, Technology and Public Policy Program Discussion Paper 9093 (Kennedy School of Government, Harvard University, 1990).

[25] F. Lichtenberg, The Impact of the Strategic Defense Initiatve on US Civilian R\&D Investment and Industrial Competitiveness, Social Studies of Science 19 (1989).

[26] F. Lictenberg, The Relationships Between Federal Contract R\&D and Company R\&D, The American Economic Review 74(2) (1984).

[27] A. Markusen, The Military Industrial Divide: Cold War Transformation of the Economy and the Rise of New Industrial Complexes (Rutgers University, 1990).

[28] D. Mowery and N. Rosenberg, Technology and the Pursuit of Economic Growth (Cambridge University Press, 1990).

[29] D. C. Mowery and N. Rosenberg, New Developments in U.S. Technology Policy: Implications for Competitiveness and International Trade Policy, Discussion Paper Series No. 166, CEPR, Stanford University, 1989.

[30] National Academy of Sciences, The Role of Government in Civilian Technology: Building a New Alliance (National Academy Press, Washington, DC, 1992).

[31] National Research Council, The Role of DOD Supporting Manufacturing Technology Development.

[32] National Research Council, Photonics: Maintaining Competitiveness in the Information Era (National Academy Press, 1988).

[33] R. Nelson and G. Wright, The Rise and Fall of American Technological Leadership, The Journal of Economic Literature (1993).

[34] M. Odden, Military Spending Erodes Real National Security, Bulletin of Atomic Scientists (June 1988).

[35] E. Poole and J. T. Bernard, Defence Innovation Stock and Total Factor Productivity, Canadian Journal of Economics 25(2) (1992).

[36] J. Reppy, Military Research and Economic Performance, TEP Conference, OECD, Paris, 1990.

[37] D. Robyn, W. W. Fletcher and J. A. Alic, Bringing Superconductivity to Market, Issues in Science and Technology (Winter 1988-89).

[38] N. Rosenberg, Perspectives on Technology (Cambridge University Press, 1976).

[39] N. Rosenberg, Inside the Back Box (Cambridge University Press, 1982). 
[40] N. Rosenberg, Civilian Spillovers from Military R\&D Spending: The American Experience Since World War II, in: H. Fusfeld and Nelson (Editors), Technical Cooperation and International Competitiveness, Proceedings of a Conference, Rensselaer Polytechnic Institute, (1988).

[41] M. Schankerman and A. Pakes, Estimates of the Value of Patent Rights in European Countries During the Post-1950 Period, The Economic Journal 96 (1986).

[42] W. Smit, Steering the Process of Military Technological Innovation, Defense Analysis, forthcoming.

[43] E. Steinmueller, Industry Structure and Government Policies in the US and Japanese Integrated Circuit Industries, CEPR Discussion Paper, Stanford University (1986).

[44] G. Tassey, Technology Infrastructure and Competitive Positions (Dordrecht, Kluwer Publishers, 1992).

[45] J. E. Tilton, International Diffusion of Technology: The Case of Semi-conductors (The Brookings Institution, Washington, DC, 1971).

[46] J. M. Utterback and A. E. Murray, The Influence of Defense Procurement and Sponsorship of Research and Development of the Civilian Electronics Industry, Center for Policy Alternatives, MIT, 1977. 